TI 2011-166/1

Tinbergen Institute Discussion Paper

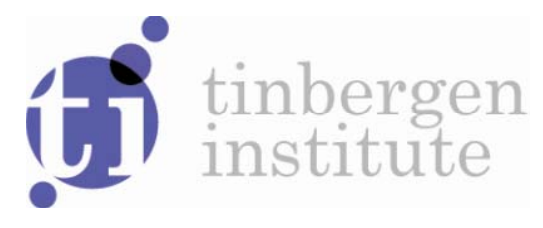

\title{
Antitrust Enforcement and Marginal Deterrence
}

Harold Houba'

Evgenia Motchenkoval

Quan Wen²

\footnotetext{
1 Faculty of Economics and Business Administration, VU University Amsterdam, and Tinbergen Institute;

2 Vanderbilt University.
} 
Tinbergen Institute is the graduate school and research institute in economics of Erasmus University Rotterdam, the University of Amsterdam and VU University Amsterdam.

More TI discussion papers can be downloaded at http://www.tinbergen.nl

Tinbergen Institute has two locations:

Tinbergen Institute Amsterdam

Gustav Mahlerplein 117

1082 MS Amsterdam

The Netherlands

Tel.: +31(0)205251600

Tinbergen Institute Rotterdam

Burg. Oudlaan 50

3062 PA Rotterdam

The Netherlands

Tel.: +31(0)10 4088900

Fax: $+31(0) 104089031$

Duisenberg school of finance is a collaboration of the Dutch financial sector and universities, with the ambition to support innovative research and offer top quality academic education in core areas of finance.

DSF research papers can be downloaded at: http://www.dsf.nl/

Duisenberg school of finance

Gustav Mahlerplein 117

1082 MS Amsterdam

The Netherlands

Tel.: +31(0)20 5258579 


\title{
Antitrust Enforcement and Marginal Deterrence
}

\author{
Harold Houba* \\ VU University Amsterdam \\ and Tinbergen Institute
}

\author{
Evgenia Motchenkova ${ }^{\dagger}$ \\ VU University Amsterdam \\ and TILEC
}

November 2011

\author{
Quan Wen \\ Vanderbilt University
}

\begin{abstract}
We study antitrust enforcement in which the fine must obey four legal principles: punishments should fit the crime, proportionality, bankruptcy considerations, and minimum fines. We integrate these legal principles into an infinitely-repeated oligopoly model. Bankruptcy considerations ensure abnormal cartel profits. We derive the optimal fine schedule that achieves maximal social welfare under these legal principles. This optimal fine schedule induces collusion on a lower price making it more attractive than on higher prices. Also, raising minimum fines reduces social welfare and should never be implemented. Our analysis and results relate to the marginal deterrence literature by Shavell (1992) and Wilde (1992).
\end{abstract}

JEL Classification: L4 Antitrust Policy, K21 Antitrust Law, D43 Oligopoly and Other Forms of Market Imperfection, C73 Stochastic and Dynamic Games; Repeated Games

Keywords: Antitrust enforcement, Antitrust Law, Cartel, Oligopoly, Repeated game

${ }^{*}$ Department of Econometrics, VU University Amsterdam, De Boelelaan 1105, $1081 \mathrm{HV}$ Amsterdam, Netherlands. Email: hhouba@feweb.vu.nl.

†Department of Economics, VU University Amsterdam, De Boelelaan 1105, 1081 HV Amsterdam, Netherlands. Email: emotchenkova@feweb.vu.nl.

${ }^{\ddagger}$ Department of Economics, Vanderbilt University, VU Station B \#351819, 2301 Vanderbilt Place Nashville, TN 37235-1819, U.S.A. Email: quan.wen@vanderbilt.edu. 


\section{Introduction}

The modern economic theory of law enforcement stems from Becker's (1968) seminal paper. The key message is that the implementation of legal rules changes the economic incentives for illegal practices and the main concern is how society should channel incentives to arrive at an efficient deterrence of such practices. This requires deterring crime only when it is efficient to do so and implementing enforcement in the most cost effective way. Antitrust regulation to deter cartels incorporated the issue of sustainable concerted illegal activities by several offenders. ${ }^{1}$ Most of the current literature, however, is rather silent on how to integrate legal principles into the economic analysis. ${ }^{2}$ Such principles reflect the society's moral values about justice and what legal rules are feasible. Legal principles may conflict with the economic principle of efficiency, which makes deterrence less effective. The central aim of this paper is to reconcile legal principles and the economic theory of law enforcement by integrating such principles into a model where one can channel incentives to arrive at the maximal feasible deterrence of illegal concerted activities.

Becker's original analysis suggests a simple rule: Deter crime only when the harm it causes is greater than the benefit accruing to the offender, and to do it by setting the fine and the probability of conviction so that the expected penalty just equals the offender's benefit. ${ }^{3}$ As this theory takes the view that increasing the rate of law enforcement entails positive social costs, while fines are socially costless, the optimal law enforcement for cartels dictates to set fines to the maximum level in order to save on inspection costs. An adaptation of this rule to antitrust law enforcement is provided by Landes (1983). In the case of cartels, benefit consists of the additional collusive profits plus any cost saving and quality improvement the coordinated practice may generate, net of any cost of enforcement, while harm consists of the consumer surplus transferred to firms in the form of collusive profits plus the utility of

\footnotetext{
${ }^{1}$ See, for example, Harrington (2004, 2005).

${ }^{2}$ Notable exceptions include Buccirossi and Spagnolo (2007) or Cooter and Ulen (2007).

${ }^{3}$ Risk aversion and legal errors could reduce the optimal fine, see e.g. Garoupa (1997, 2001), Polinsky and Shavell (1984, 1991, 1992, 2000).
} 
the foregone consumption due to the higher price, i.e., the deadweight loss. It has been argued by many researchers, such as Werden and Simon (1987) and Buccirossi and Spagnolo (2007), that the cartel's benefit from price-fixing is smaller than the harm it causes and that there are no such collusive infringements that may enhance social welfare. Hence, according to this simple rule, the efficient expected fine should be set at the lowest level that deters all possible cartels or all possible collusive prices and to set fines to the maximum level in order to save on inspection costs.

Buccirossi and Spagnolo (2007) argue that this simple policy prescription is too much in contrast with current practices of antitrust law enforcement in both the US and the EU. First, legislation sets restrictive ceilings to the maximum applicable fine due to bankruptcy considerations. Second, an important legal principle is that punishments should be based on the gravity of the offense in order to reflect society's harm and illegal gains. For antitrust, the legislation attempts to relate the fine to a rough measure of gravity that is approximated by the cartel's illegal gains in the US and by the cartel overcharge in the EU. These gravity measures aim to capture the consequences of cartel behavior for the colluding firms and their victims. Third, an equally important legal principle is the principle of proportionality; the regulator should not take any action that exceeds the one which is just necessary to achieve the objective (see Fish, 2008). In terms of the fine structures, this principle implies that the fine should not be in excess of the lowest fine that suffices to prevent criminal activities.

Ceilings on antitrust fines have been analyzed by Buccirossi and Spagnolo (2007) and Wils (2007). They argue that the ceilings on antitrust fines in both the US and the EU are insufficient to deter cartels. The ceiling makes antitrust policies either completely ineffective, such that the cartel can sustain all prices including the monopoly price, or at best partially effective but in such a way that only low prices are deterred, but the high prices are still sustainable by the cartel. This raises the issue whether such negative result is inevitable in the presence of legal ceilings on fines.

One of our main contributions is to revise previous policy prescriptions for an extension 
of the model in Buccirossi and Spagnolo (2007) in which the above legal principles are accounted for. In our model, the price is a continuous variable that is set strategically by the cartel to maximize its profit given the antitrust enforcement. Antitrust enforcement is endogenous and it is set strategically so that social welfare is maximized while obeying the legal principles. Technically speaking, the fine structure is a function of the cartel price and other parameters of the model. Optimizing over the space of all feasible fine schedules is a challenging mathematical problem that we solve by sound economic reasoning alone without the need of complicated mathematics.

Our major result is that even in the presence of legal ceilings, it is possible to design a more effective fine structure that is welfare improving when compared to the policy prescriptions currently available in the literature. We demonstrate this by constructing the most effective optimal fine schedule that satisfies the four legal principles. This fine schedule induces the lowest cartel price that is optimal for the cartel and, hence, reduces the dead-weight loss to its lowest achievable level. This improvement is achieved by making collusion on lower prices more attractive than collusion on higher prices. This result and the derived optimal fine schedule can be related to the literature on marginal deterrence by Stigler (1971), Shavell (1992), and Wilde (1992). Shavell (1992) and Wilde (1992) analyze individual offenders and only two illegal acts under a constant legal upper bound. They derive that the fine for a more harmful offence should be set equal to the legal upper bound, while less harmful crime should receive a lower punishment. This fine schedule induces offenders to choose the least harmful act. Our analysis shows how to generalize the results of Shavell (1992) and Wilde (1992) to the case of a non-constant legal upper bound and group violations with multiple concerted illegal actions in the context of antitrust enforcement.

The rest of this paper is organized as follows. Section 2 discusses the legal principles and how we implement them. Section 3 outlines the model. The optimal fine schedule is derived in Section 4. Section 5 provides concluding remarks. 


\section{Legal Principles of Antitrust}

Current legislations in the US and EU restrict fines based on legal and economical principles such as punishments should fit the crime, proportionality, bankruptcy considerations, and minimum fines. In this section, we discuss these four principles and how to incorporate them into our analysis.

Punishments Fit the Crime: Antitrust guidelines in the US and EU are founded on the legal principle that punishment should fit the crime, see DOJ (2010) and EC (2006). In practice, this principle translates into higher fines for higher-gravity offenses. Generally speaking, the gravity of an offence is related to both the harm caused by the offense and the cartel's illegal gains. In the US, the gravity is measured by the cartel's illegal gains, while in the EU, it is approximated by the cartel overcharge.

Principle of Proportionality: An important principle of current legislation is the principle of proportionality that states that regulators should not take any action that exceeds the one which is just sufficient to achieve the same outcome, see e.g. Fish (2008). Interpreting this principle in terms of the fine structure, it requires that the fine should not be more than the lowest possible fine that would induce the same market outcome. If fines are considered to be socially costless, there is no reason to adopt this principle. However, excessive fines may amplify the possible negative impact of antitrust enforcement, which can stem from unobservable legal errors. Hence, the rationale for adopting the principle of proportionality is to minimize any potential undesirable impact of the antitrust policy.

Bankruptcy Considerations: Both the US and EU legislation impose ceilings on fines. These ceilings are justified on the ground that legislators do not want to jeopardize the financial stability of the offending firms. Besides employment considerations, high fines that cause bankruptcy are against the ultimate goal of antitrust law because such high fines would reduce the number of active competitors in the market. 
In the EU, fines are limited up to $10 \%$ of overall total annual turnover, see EC (2006). Total turnover is indirectly related to the illegal gains or price-markups in the markets corrupted by cartel agreements, because it consists of the total sales over all the product markets in which the company operates, while only some of these markets may be involved in the collusive agreement. There is no formal legal upper bound on the antitrust fines in the US. However, in many cases, such as the UCAR 1993 case, fines were reduced due to firms' inability to pay. In such a setting, the existence of an implicit ceiling on fines, which is determined by the firms' limited liability, can be argued.

Minimum Fines: According to the current sentencing guidelines in the US, the base fine can be zero for some mild offenses, see DOJ (2010). Moreover, rewarding firms that violate antitrust law is not possible according to the current rules both in the US and the EU. This indicates that imposing no or a zero fine has to be regarded as the minimum fine.

Modelling Legal Antitrust Principles: We analyze fines that satisfy the legal principles listed above in an oligopoly model of price competition. Current antitrust legislation relates the fine to a measure of gravity that is approximated by the cartel's illegal gains or by the cartel overcharge. ${ }^{4}$ Because both cartel's illegal gains and overcharge are positively related to the relevant cartel price, we model the fine schedule as a function of cartel price to accommodate the current practice in the US and EU. As in Becker (1968) and Posner (1976), the optimal antitrust enforcement consists of a fine schedule and effort level of inspection and prosecution that maximize the social welfare. In addition, the fine schedule must satisfy the four principles discussed above.

The bankruptcy considerations and the minimum fines impose upper and lower bounds on the fine schedule. The upper bound is a given function of the cartel price in order to

\footnotetext{
${ }^{4}$ The 2006 Guidelines revise those adopted in 1998, with a view to increasing the deterrent effect of fines. Council Regulation 1/2003 (as with Council Regulation 17/62 before it) provides that companies may be fined up to $10 \%$ of their total annual turnover. Within this limit, the revised Guidelines provide that fines may be based on up to $30 \%$ of the company's annual sales to which the infringement relates. In particular, the basic amount of the fine will be related to a proportion of the value of sales, depending on the degree of gravity of the infringement, multiplied by the number of years of infringement.
} 
capture current guidelines in the US and EU. By doing so, our approach accommodates for the three main interpretations of the current guidelines: a constant upper bound, a percentage of annual overall turnover, and bounds related to the cartel's illegal gains. With respect to the minimum fine, the fine schedule is bounded by a legal lower bound in order to capture the feature that rewards are not allowed in the current guidelines in the US and EU.

The principle that punishment should fit the crime implies that a higher cartel price should cause a higher fine. In other words, the fine schedule should be non-decreasing in order to incorporate the possibility that a range of mild offenses are not fined. The legal principle of proportionality requires that the fine should be kept to the minimum that is just necessary to induce the best social outcome within the domain of fine schedules that satisfy the other three principles.

\section{The Model}

Consider an infinitely-repeated oligopoly model with discounting in the presence of antitrust enforcement. Given the probability to be detected and the fine structure, if the firms collude, they will be detected probabilistically and fined according to the fine structure. We study a stationary subgame perfect equilibrium of this repeated game model where the cartel maximizes its present value of the stream of profits under the antitrust policy that satisfies the four legal principles discussed in the previous section.

In every period, $n \geq 2$ firms compete in a symmetric Bertrand oligopoly model. ${ }^{5}$ Let $\pi\left(p_{1}, \ldots, p_{n}\right)$ be a firm's profit under price profile $\left(p_{1}, \ldots, p_{n}\right)$, and denote $\pi(p) \equiv \pi_{i}(p, \ldots, p)$ when the firms collude at price $p$. Let $\pi^{o p t}(p) \equiv \sup _{p^{\prime}} \pi\left(p^{\prime}, p, \ldots, p\right)$ be the least upper bound of a firm's profit from a unilateral deviation against the cartel price $p$. Denote the symmetric Nash equilibrium price and the maximal symmetric collusive price by $p^{N}$ and $p^{M}$, respectively. Assume that $\pi(p)$ and $\pi^{o p t}(p)$ are continuous and strictly increasing in

\footnotetext{
${ }^{5}$ This model includes homogeneous products, heterogeneous products, and spacial price competition Our analysis can be adapted for quantity competition.
} 
$p \in\left[p^{N}, p^{M}\right]$, and $\pi^{o p t}(p)>\pi(p)$ for all $p \in\left(p^{N}, p^{M}\right]$. Without loss of generality, we normalize this oligopoly model such that $\pi\left(p^{N}\right)=0$ and interpret $\pi(p)$ as the net profit above $\pi\left(p^{N}\right)$.

Antitrust enforcement consists of the antitrust authority's (AA) effort level to detect and prosecute the cartel and a fine structure. A higher effort of detection/prosecution leads to a higher probability to detect the cartel, but associates with a higher cost. Due to limited resources of the AA, assume that the probability to detect the cartel is given by $\beta \in[0,1)$. Note that $\beta=0$ is equivalent to a situation with no antitrust enforcement.

The fine structure is modeled as a function of the cartel price. If the firms are found guilty of sustaining cartel price $p \in\left(p^{N}, p^{M}\right]$, then every firm will have to pay the one-time fine $\xi(p)$. Here we maintain the specification of Rey (2003) that only misconduct in the current period is prosecuted. The fine schedule $\xi(\cdot)$ is a function of $p$ that obeys the four legal principles discussed in the previous section. It is continuous, nondecreasing, satisfies proportionality, and the legal upper and lower bounds. The legal upper bound $\bar{\xi}(\cdot)$ is assumed to be continuous and nondecreasing in $p$.

The legal principle of proportionality requires some explanation. A fine schedule that is limited by an insufficient legal upper bound is ineffective to deter some cartel prices and, hence, the cartel will form. Given $\beta$ and $\xi(\cdot)$, the cartel will choose the optimal cartel price that maximizes the present value of its member's profit with discount factor $\delta \in(0,1)$. The fine schedule $\xi(\cdot)$ satisfies the legal principle of proportionality if there does not exist another fine schedule $\hat{\xi}(\cdot) \leq \xi(\cdot)$ such that $\hat{\xi}(\cdot)$ induces the same optimal cartel price as $\xi(\cdot)$ does. This class of fine schedules accommodates the current practice of fines that are related to either the illegal profits or cartel overcharge through the gravity of the offence as described in OECD (2002), EC (2006), and DOJ (2010).

Observe that the static Nash equilibrium price $p^{N}$ is always sustainable by subgame perfect equilibrium for all $\delta \in(0,1)$, which is also the first-best outcome in the model outlined above. We now discuss a stationary subgame perfect equilibria supported by the 
following modified trigger strategy profile in the presence of antitrust enforcement: The firms collude at price $p>p^{N}$ in the first period and continue to set price $p$ as long as no firm deviates from the cartel price $p$. Any price deviation by some of the firms will lead to the static Nash equilibrium price $p^{N}$ in every period thereafter. The behavior after any deviation reflects a permanent breakdown of trust among the firms, and without trust, the firms will not be able to form a cartel anymore. As in Motta and Polo (2003), here we assume that the cartel will continue every time it is detected and fined. Alternatively, Harrington (2004, 2005) and Houba, Motchenkova, and Wen (2012) consider situations where the cartel will dissolve with either certainty or some probability each time it is detected. Assuming the cartel will reestablish after each time it is detected is consistent with the cartel's profitmaximizing behavior. It is worthwhile to point out that how the cartel behaves after it is detected does not change the qualitative aspect of our analysis and results.

Let $v(p, \xi)$ be the present value of a firm's expected profit from the above strategy profile. It equals the current illegal net profits $\pi(p)$, minus the expected fine $\beta \xi(p)$, plus the expected continuation value $\delta v(p, \xi)$. Solving for $v(p, \xi)$ yields the following profit function for every cartel member:

$$
v(p, \xi)=\frac{\pi(p)-\beta \xi(p)}{1-\delta} .
$$

As in Motta and Polo (2003), price-deviating firms will not be prosecuted. ${ }^{6}$ Given the modified trigger strategy profile, the profit of any firm from a unilateral deviation is equal to the short-term net gain $\pi^{o p t}(p)$ in the current period, minus an expected fine of zero (no prosecution), plus the normalized profit from $p^{N}$ forever. The necessary and sufficient condition to support cartel price $p \in\left(p^{N}, p^{M}\right]$ by a subgame perfect equilibrium is

$$
v(p, \xi)=\frac{\pi(p)-\beta \xi(p)}{1-\delta} \geq \pi^{o p t}(p) .
$$

An optimal cartel price maximizes the present value of each firm's expected profit and the

\footnotetext{
${ }^{6}$ Alternative assumptions such as the possibility of prosecuting price-deviating firms would only relax the equilibrium condition for collusion to be sustainable. Hence, our results will not qualitatively change if such alternative assumption were imposed.
} 
set of optimal cartel prices is

$$
P^{C}(\xi)=\arg \max _{p \in\left(p^{N}, p^{M}\right]} v(p, \xi) \quad \text { subject to } v(p, \xi) \geq \pi^{o p t}(p) .
$$

Observe that a lower cartel price implies a lower deadweight loss, or a higher social welfare. Hence, our objective is to identify the optimal fine schedule that induces the lowest optimal cartel price in the class of fine schedules that satisfy the four legal principles. The design of the optimal fine schedule takes into account the optimal reaction by the cartel to the antitrust enforcement.

\section{The Optimal Fine Schedule}

In this section, we will characterize the optimal fine schedule in the following three steps. First, we identify the profit level the cartel can guarantee to each firm when facing any fine schedule that satisfies the four legal principles. Second, given the legal lower bound of a fine schedule, we derive the lowest possible cartel price at which each firm receives the minmax profit we identified in step one. Lastly, we provide a fine schedule that satisfies the four legal principles and induces the minimal cartel price. We will show that this fine schedule is the lowest fine schedule that also induces this minimal cartel price, and it is the optimal fine schedule.

\subsection{The Minmax Cartel Profit}

The rationale of the Beckerian tradition is that the expected loss of being punished should outweigh the expected benefit of committing the crime, see e.g., Becker (1968) or Posner (1976). The condition of marginal deterrence in Stigler (1970) states that the marginal benefit of an illegal activity should be equal to the marginal expected fine to deter such an activity. In its most elementary form, this suggests $\beta \xi(p) \geq \pi(p)$ in our antitrust enforcement problem, where the Beckerian tradition and Stigler's marginal deterrence are equivalent. If the AA were able to set the fine high enough, such as $\xi(p)>\frac{1}{\beta} \pi(p)$ for all $p>p^{N}$, it would be unprofitable for the firms to collude because equilibrium condition (2) fails for all $p>p^{N}$. 
Buccirossi and Spagnolo (2007) and Wils (2007), however, point out that the current inspection efforts and the existing upper bounds on fines in both the US and EU are insufficient to deter cartels. This suggests that the existing legal upper bound $\bar{\xi}(p)$ not only fails the Beckerian structure but also is not high enough to deter cartel formation so that

$$
v(p, \bar{\xi}) \geq \pi^{o p t}(p) \Leftrightarrow \bar{\xi}(p) \leq \frac{1}{\beta}\left[\pi(p)-(1-\delta) \pi^{o p t}(p)\right]
$$

for some $p \in\left(p^{N}, p^{M}\right]$. Accordingly, we assume that the exogenous legal upper bound $\bar{\xi}(p)$ satisfies (4), so that any fine schedule $\xi(p)$ bounded by the legal upper bound $\bar{\xi}(p)$ is also insufficient to deter all cartel prices.

Recall that we are searching for the optimal fine schedule that satisfies the four legal principles, including the legal upper bound. For any fine schedule $\xi(p) \leq \bar{\xi}(p)$, observe that if condition (4) is satisfied at $p>p^{N}$, then

$$
v(p, \xi)=\frac{\pi(p)-\beta \xi(p)}{1-\delta} \geq \frac{\pi(p)-\beta \bar{\xi}(p)}{1-\delta}=v(p, \bar{\xi}) \geq \pi^{o p t}(p),
$$

which implies that such $p$ can also be sustained as a cartel price when the fine schedule $\xi(p)$ is imposed. Inequality (5) also implies that if the firms set the corresponding optimal cartel price, each cartel member receives no less when facing $\xi(p)$ than when facing the upper legal bound $\bar{\xi}(p)$. In other words, when facing a fine schedule that obeys the legal upper bound, each cartel member should receive at least what it can receive when facing the legal upper bound and setting the corresponding optimal cartel price.

Proposition 1 For all fine schedules $\xi(\cdot) \leq \bar{\xi}(\cdot)$, we have

$$
\max _{p: v(p, \xi) \geq \pi^{o p t}(p)} v(p, \xi) \geq \max _{p: v(p, \bar{\xi}) \geq \pi^{o p t}(p)} v(p, \bar{\xi}) .
$$

Proof. Take any optimal cartel price when facing the fine schedule $\bar{\xi}(\cdot)$,

$$
p^{C} \in \arg \max _{p} v(p, \bar{\xi}) \quad \text { subject to } v(p, \bar{\xi}) \geq \pi^{o p t}(p) .
$$

Because $\xi\left(p^{C}\right) \leq \bar{\xi}\left(p^{C}\right)$, we have $v\left(p^{C}, \xi\right) \geq v\left(p^{C}, \bar{\xi}\right) \geq \pi^{o p t}(p)$, so $p^{C}$ can also be sustained as a cartel price if the fine schedule is $\xi(p)$. Note that the left-hand side of $(6)$ is greater than or equal to $v\left(p^{C}, \xi\right) \geq v\left(p^{C}, \bar{\xi}\right)$, which is the right-hand side of (6). 
In fact, the right-hand side of (6) is at least what the cartel can guarantee each member when facing any function that obeys the legal upper bound. It plays an important role in finding the optimal fine schedule. Accordingly, we denote this minmax cartel profit as

$$
\begin{aligned}
v^{*} & =\max _{p} v(p, \bar{\xi}) \quad \text { subject to } v(p, \bar{\xi}) \geq \pi^{o p t}(p) \\
& =\min _{\xi \leq \bar{\xi}} \max _{p} v(p, \xi) \quad \text { subject to } v(p, \xi) \geq \pi^{o p t}(p) .
\end{aligned}
$$

Under the legal upper bound $\bar{\xi}(\cdot)$, the condition for sustainable cartel prices requires that $v(\cdot, \bar{\xi}) \geq \pi^{o p t}(\cdot)$. Figure 1 illustrates both $v(\cdot, \bar{\xi})$ and $\pi^{\text {opt }}(\cdot)$, together with the range of sustainable cartel prices between the square brackets on the price axis. Under the legal upper bound $\bar{\xi}(\cdot)$, the cartel sets an optimal cartel price $p^{*}$ in this range and each firm obtains $v^{*}$.

The minmax cartel profit $v^{*}$ plays a prominent role in determining the optimal fine schedule. It can be viewed as the cartel's security level or the lowest maximal cartel profit for all fine schedules that are bounded by the legal upper bound. More specifically, for any fine schedule $\xi(\cdot)$ that is bounded by the legal upper bound $\bar{\xi}(\cdot)$, a firm's profit $v(\cdot, \xi)$ is always bounded from below by $v(\cdot, \bar{\xi})$. Because $\pi^{\text {opt }}(\cdot)$ does not depend on the fine schedule, any cartel price under the legal upper bound, such as $p^{C}(\bar{\xi})$, can also be sustained as a cartel price under such a fine schedule $\xi(\cdot)$. Therefore, under fine schedule $\xi(\cdot) \leq \bar{\xi}(\cdot)$, the cartel is able to obtain at least as $v^{*}$ by setting price at $p^{*}$ :

$$
v\left(p^{*}, \xi\right) \geq v\left(p^{*}, \bar{\xi}\right)=v^{*} \geq \pi^{o p t}\left(p^{*}\right)
$$

In general, however, each firm may receive more than $v^{*}$ when facing a fine schedule that is less than the legal upper bound.

\subsection{The Minimal Cartel Price}

Imposing the legal upper bound will certainly induce the minmax cartel profit $v^{*}$ to every firm. However, given that it is impossible to prevent the cartel under the legal upper bound, the objective of antitrust enforcement is not to minimize the cartel profit, but rather to minimize the harm caused by the cartel. Given a fine schedule must also satisfies the three other 


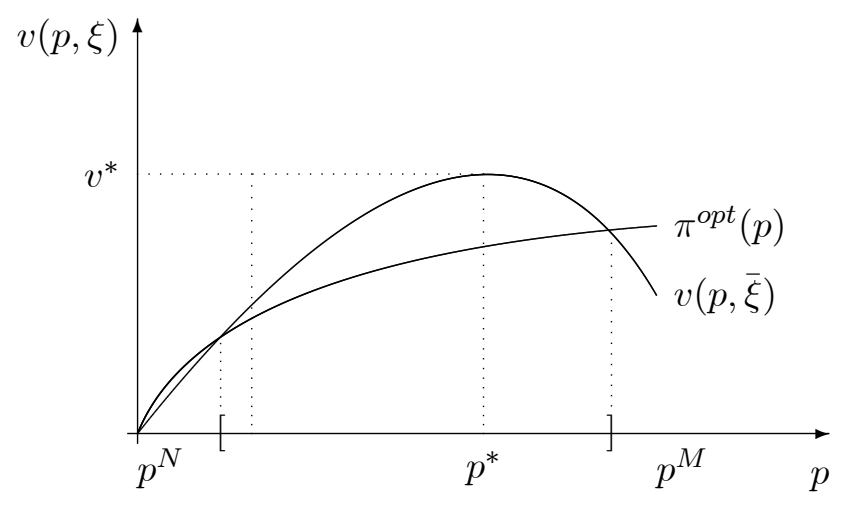

Figure 1: The minmax cartel profit $v^{*}$ and the optimal cartel price $p^{*}$

legal principles, the question is how to minimize the harm caused by the cartel given that each firm must receive a profit that is at least the minmax cartel profit. In this subsection, we identity this achievable minimal cartel price.

Recall the value function (1) and any fine schedule must also be bounded from below by some exogenous legal lower bound, normalized to be zero. For $\xi(p) \geq 0$, we have

$$
v(p, \xi)=\frac{\pi(p)-\beta \xi(p)}{1-\delta} \leq \frac{\pi(p)}{1-\delta} .
$$

Proposition 1 asserts that no matter what fine is imposed, the optimal cartel profit is at least $v^{*}$. Therefore, in order for any $p \in\left(p^{N}, p^{M}\right]$ to be a possible optimal cartel price, it must be the case that

$$
v^{*} \leq v(p, \xi) \leq \frac{\pi(p)}{1-\delta} \Leftrightarrow \pi(p) \geq(1-\delta) v^{*} .
$$

Given the monotonicity of the profit function $\pi(p)$ for $p \in\left(p^{N}, p^{M}\right]$, there is a unique price $\hat{p}=\pi^{-1}\left((1-\delta) v^{*}\right)$ at which (8) holds with equality, where $\pi^{-1}(\cdot)$ is the inverse function of $\pi$ for $p \in\left(p^{N}, p^{M}\right]$. Therefore, given the constraint that $\xi(\cdot) \geq 0$, the cartel must set its price equal to $\hat{p}$ or above in order to ensure each member's profit is at least the minmax cartel profit $v^{*}$. Now we argue that such $\hat{p}$ can be sustained as a cartel price if $\xi(\hat{p})=0$. Observe that

$$
v(\hat{p}, 0)=\frac{\pi(\hat{p})}{1-\delta}=v^{*}=v\left(p^{*}, \bar{\xi}\right)=\frac{\pi\left(p^{*}\right)-\beta \bar{\xi}\left(p^{*}\right)}{1-\delta} \geq \pi^{o p t}\left(p^{*}\right),
$$


where the last inequality is due to $(7)$. Because $\bar{\xi}\left(p^{*}\right) \geq 0$, the monotonicity of $\pi(\cdot)$ implies that $\pi(\hat{p}) \leq \pi\left(p^{*}\right)$, which in turn implies that $\hat{p} \leq p^{*}$. Due to the assumption that $\pi^{\text {opt }}(\cdot)$ is also monotonically increasing, (9) implies that

$$
v(\hat{p}, 0) \geq \pi^{o p t}\left(p^{*}\right) \geq \pi^{o p t}(\hat{p})
$$

which means that $\hat{p}$ can be sustained as a cartel price. In fact, $\hat{p}$ is the lowest possible optimal cartel price when the firms face any fine schedule that satisfies the four legal principles. For this reason, we call $\hat{p}$ the minimal cartel price. This result is formally presented as

Proposition 2 For any fine schedule $\xi(\cdot)$ that satisfies the four legal principles, any optimal cartel price is bounded from below by the minimal cartel price $\hat{p}=\pi^{-1}\left((1-\delta) v^{*}\right)$.

Built upon Figure 1, Figure 2 illustrates how the minimal cartel price is determined by the minmax cartel profit. Recall that minmax cartel profit $v^{*}$ is the maximal cartel profit when the legal upper bound $\bar{\xi}(\cdot)$ is imposed. Given the monotonicity of profit function $v(p, 0)=\pi(p) /(1-\delta)$, the minimal cartel price is the one at which each firm receives exactly the minmax cartel profit when the legal lower bound 0 is imposed. For simplicity, we choose not to illustrate the equilibrium condition as we have shown that if $\xi(\hat{p})=0$, the minimal cartel price $\hat{p}$ can be sustained as an equilibrium price by the modified trigger strategy profile.

In searching for the optimal fine schedule that satisfies the four legal principles where the legal upper bound is insufficient to deter cartel activity, the objective of antitrust enforcement should shift to minimize the harm caused by the cartel. This translates into minimization of the optimal cartel price in order to take into account the cartel's response to the fine schedule set. Proposition 2 shows that within the class of fine schedules considered, it is impossible to reduce the cartel price below the minimal cartel price. Now the question is whether it is feasible to induce this minimal cartel price with a fine schedule that not only satisfies the upper and lower bounds, but also the monotonicity and, more importantly, the proportionality. If such a fine schedule exists and indeed induces the minimal cartel price, 


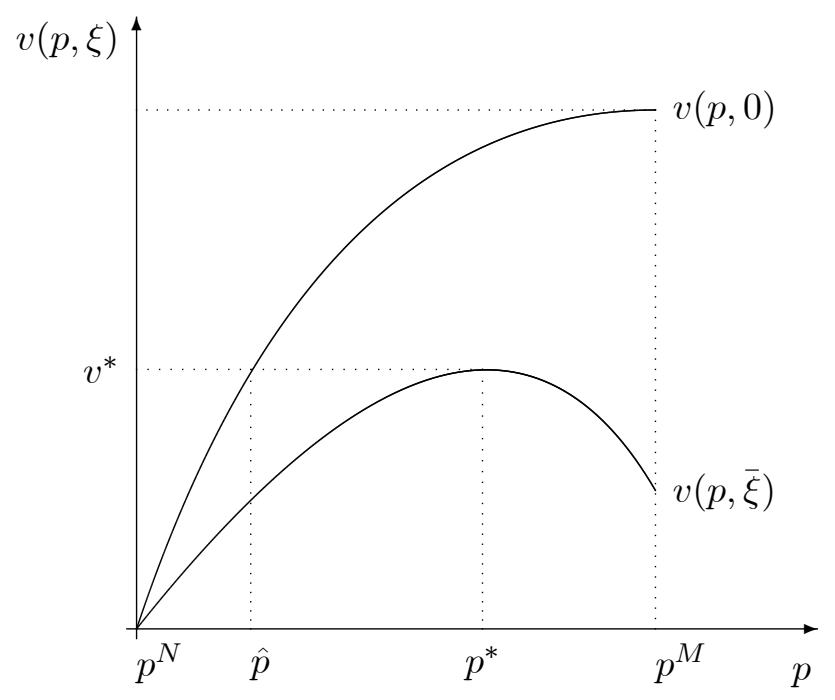

Figure 2: The minimal cartel price $\hat{p}$.

it is the optimal fine schedule under the four restrictions imposed by the legal rules and conventions.

\subsection{Characterization of the Optimal Fine Schedule}

We now derive a fine schedule under which the minimal cartel price is an optimal cartel price. As we have argued, such a fine schedule induces the lowest possible optimal cartel price that is the second-best outcome given that the cartel cannot be completely prevented due to the legal upper bound on fine schedules. Hence, the fine schedule we derive is indeed the optimal fine schedule. In doing so, we utilize all four legal principles, namely monotonicity, lower and upper legal bounds, and proportionality.

In order to achieve the minimal cartel price $\hat{p}$, it is necessary that it can be sustained as a cartel price and that each firm receives the minmax cartel profit $v^{*}$. This requires that the fine should be set to 0 when the firms collude at the minimal cartel price $\hat{p}$. Because the fine schedule must satisfy monotonicity and the legal lower bound of 0 , we conclude that $\xi(p)=0$ for all $p \in\left[p^{N}, \hat{p}\right]$. For this range of prices, whether they can be sustained as cartel prices or not, monotonicity and the legal lower bound are binding in determining the optimal fine schedule. 
Next consider the price range $\left(\hat{p}, p^{M}\right]$. If the legal upper bound $\bar{\xi}(\cdot)$ were imposed, the cartel would receive at most a profit of $v^{*}$ by selecting a cartel price $p \in\left(\hat{p}, p^{M}\right]$. Given the minmax cartel profit $v^{*}$ from setting the price at the minimal cartel price $\hat{p}$, the necessary and sufficient condition for $\hat{p}$ to be an optimal cartel price is that for all $p \in\left(\hat{p}, p^{M}\right]$

$$
\text { either } v(p, \xi) \leq v^{*} \quad \text { or } \quad v(p, \xi)<\pi^{o p t}(p) \text {. }
$$

Condition (10) asserts that either $p$ can be sustained as a cartel price but each firm does not receive more profit than $v^{*}$, or $p$ cannot be sustained at all. Rewriting (10) yields

$$
\text { either } \xi(p) \geq \frac{1}{\beta}\left[\pi(p)-(1-\delta) v^{*}\right] \quad \text { or } \quad \xi(p)>\frac{1}{\beta}\left[\pi(p)-(1-\delta) \pi^{o p t}(p)\right] .
$$

The legal principle of proportionality requires that the fine is just high enough to reduce the cartel profit either to $v^{*}$ for any $p \in\left(\hat{p}, p^{M}\right]$, or to upset the equilibrium condition (2). Moreover, in order to obey this principle we need to identify the minimum of these two right-hand sides. This yields two cases in (11) depending whether $\pi^{o p t}\left(p^{M}\right) \leq v^{*}$ or not.

This distinction can be related to the level of the legal upper bound $\bar{\xi}(\cdot)$. In case the legal upper bound is relatively low, $v^{*}$ is relatively high and we have $\pi^{\text {opt }}\left(p^{M}\right) \leq v^{*}$. The optimal cartel price is then solely driven by the minmax profit level, and breaking cartel sustainability is irrelevant in the determination of the optimal fine schedule, which is reflected by the fact that all cartel prices are sustainable. In the other case, the legal upper bound is relatively high, $v^{*}$ is relatively low and we have $\pi^{o p t}\left(p^{M}\right)>v^{*}$. Then, the sustainability condition also plays a key role in the determination of the optimal fine schedule. We treat the first case in this section, derive the corresponding optimal fine schedule, and utilize it to illustrate our main results and contributions to the literature, and the policy implications. The analysis of the second case has similar policy implications, however, it involves technical complications related to existence of the optimal fine schedule on some intervals of prices. For that reason, we postpone the analysis of this case to the Appendix.

In the remainder of this section, we consider that case of $\pi^{\text {opt }}\left(p^{M}\right) \leq v^{*}$. Due the monotonicity of $\pi^{\text {opt }}(p)$, we have that $\pi^{\text {opt }}(p) \leq v^{*}$ for all $p \in\left[p^{N}, p^{M}\right]$. Consequently, (11) 


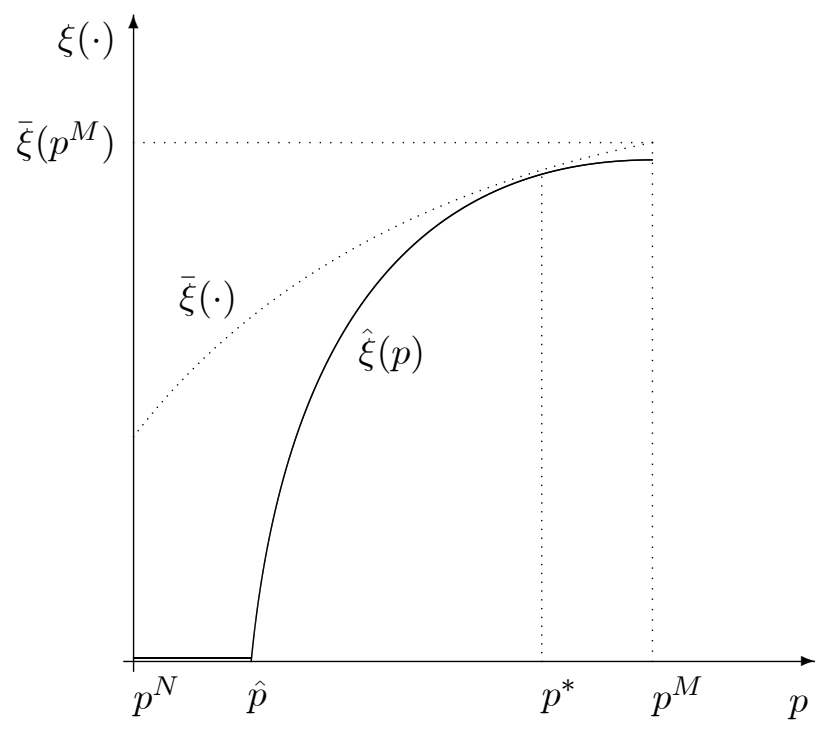

Figure 3: The optimal fine $\hat{\xi}$ (solid) and the legal upper bound $\bar{\xi}$ (dotted).

simplifies to $\xi(p) \geq \frac{1}{\beta}\left[\pi(p)-(1-\delta) v^{*}\right]$, where the right-hand side is monotonic, continuous, and obeys both legal bounds. The legal principle of proportionality requires that the fine schedule is just high enough to reduce the cartel profit to $v^{*}$ for any $p \in\left(\hat{p}, p^{M}\right]$ and, therefore, equality must hold. This gives us the optimal fine schedule for $p \in\left[\hat{p}, p^{M}\right]$. Together with the optimal fine schedule for $p \in\left(p^{N}, \hat{p}\right)$, we obtain Proposition 3. The resulting optimal fine schedule is illustrated in Figure 3.

Proposition 3 When $\pi^{\text {opt }}\left(p^{M}\right) \leq v^{*}$, the optimal fine schedule is given by

$$
\hat{\xi}(p)= \begin{cases}0, & \text { for } p^{N} \leq p \leq \hat{p}, \\ \frac{1}{\beta}\left[\pi(p)-(1-\delta) v^{*}\right], & \text { for } \hat{p}<p \leq p^{M} .\end{cases}
$$

Proof. Because $\pi(\hat{p})=(1-\delta) v^{*}$ by Proposition 2, we have

$$
\lim _{p \rightarrow \hat{p}^{+}} \hat{\xi}(p)=\frac{1}{\beta}\left[\pi(\hat{p})-(1-\delta) v^{*}\right]=0,
$$

hence, $\hat{\xi}(\cdot)$ in (12) is monotonic and continuous. From the construction, we know that such a fine schedule obeys the legal lower and upper bounds. Notice that at $p^{*} \in\left[\hat{p}, p^{M}\right]$, the optimal fine $\hat{\xi}\left(p^{*}\right)$ is equal to the legal upper bound $\bar{\xi}\left(p^{*}\right)$. If $\hat{\xi}(\cdot)$ is imposed, the minimal 
cartel price $\hat{p}$ is an optimal cartel price because any other price either cannot be sustained as a cartel price or each firm will receive at most the minmax cartel profit.

Recall that in the presence of the legal upper bound the first-best fine schedule is infeasible and antitrust enforcement is insufficient to deter cartel activity. In this case, some cartel prices can be sustained by the cartel and society incurs a deadweight loss. The important question is how to keep the deadweight loss minimal given the legal upper bound. According to Proposition 3, the effectiveness of the fine schedule in reducing the optimal cartel price can be maximally improved by adapting fine schedule (12). Figure 3 illustrates that this fine schedule satisfies all four legal principles. Within this class of fine schedules, it is the only one that achieves the smallest attainable optimal cartel price $\hat{p}$. Fine schedule (12) induces the cartel to set $\hat{p}$ as its optimal cartel price. This price lies strictly between the Nash equilibrium price $p^{N}$ and the optimal cartel price $p^{*}$ when the legal upper bound is imposed. This reduces the deadweight loss caused by the cartel.

The maximal reduction of the optimal cartel price is achieved by making all prices in the range between $\hat{p}$ and $p^{M}$ as attractive as $p^{*}$ by reducing the fine below the legal upper bound. Moreover, fine schedule (12) does not punish mild offences of collusion on cartel prices below $\hat{p}$. This result supports the procedure of determination of the base fine in the current US sentencing guidelines, see DOJ (2010), where offences of mild gravity would be assigned a base fine of zero. Note that the value function under $\hat{\xi}(\cdot)$ is given by

$$
v(p, \hat{\xi})= \begin{cases}v(p ; 0), & \text { for } p^{N} \leq p \leq \hat{p} \\ v^{*}, & \text { for } \hat{p}<p \leq p^{M}\end{cases}
$$

which is illustrated in Figure 4.

Proposition 3 describes the unique SPE outcome supported by the modified trigger strategy profile. Even if some prices above the minimal cartel price $\hat{p}$ can be sustained by the cartel, they are all optimal in the sense that these yield the same profit $v^{*}$ to the cartel. In this equilibrium, the cartel selects the smallest optimal cartel price. There are practical reason why the cartel may prefer to choose this smallest optimal cartel price, such as increase 


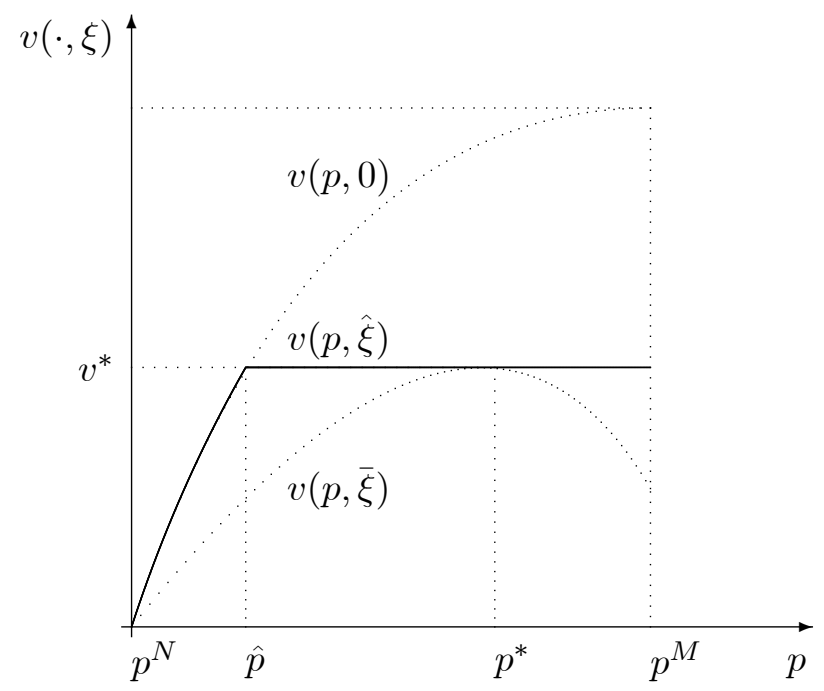

Figure 4: The value function $v(p, \hat{\xi})$ under the optimal fine $\hat{\xi}(p)$.

in the popularity of the product. Furthermore, if the cartel does not choose this smallest optimal cartel price, the AA would have an incentive to increase the fine slightly higher than $\hat{\xi}(p)$ for any price $p>\hat{p}$, so that the cartel would not choose such price $p>\hat{p}$.

For the case of a differentiable profit function, the optimal fine schedule for cartel prices in the upper/second range satisfies the condition of marginal deterrence in Stigler (1970) that states that the marginal benefit of the offense should be equal its marginal expected cost. Even in the absence of differentiability, marginal deterrence holds in the following sense. The cartel has no incentive to set a price in the lower range of prices because the present value of profits for each individual firm is strictly increasing in the cartel price on this range due to the zero fine. Also, this present value is less than the security level and, hence, these cartel prices are not optimal.

These insights also relate to the results in Block, Nold, and Sidak (1981) where the design of the optimal (differentiable) fine schedule should be such that the condition of marginal deterrence is achieved on $\left[p^{N}, p^{M}\right]$. Application of their ideas to our setting would imply that the optimal fine schedule solves the differential equation $\beta \xi^{\prime}(p)=\pi^{\prime}(p)$ for $p \in\left[\hat{p}, p^{M}\right]$ under the additional condition $\xi\left(p^{*}\right)=\bar{\xi}\left(p^{*}\right)$ instead of $\xi\left(p^{M}\right)=\bar{\xi}\left(p^{M}\right)$. In case the differential equation would also be solved for $p \in\left[p^{N}, \hat{p}\right)$, it violates the legal lower bound. Stigler (1970) 
and Block, Nold, and Sidaket (1981) are silent on the issue of sustainability of concerted illegal actions and, hence, our results generalize their analysis to include such concerted actions. In addition, we also extend the analysis to nondifferentiable profit functions and nonconstant legal upper bounds. Note that our results directly apply to individual illegal actions in antitrust enforcement by ignoring the equilibrium condition in our model. Therefore, both individual and group violations with concerted illegal actions are integrated into one unifying framework.

Before we relate our results to the marginal deterrence studied by Shavell (1992) and Wilde (1992), we first discuss the special case of a constant legal upper bound in our model. Let $\bar{\xi}(p)=\bar{\xi}$ for all $p \in\left[p^{N}, p^{M}\right]$, then profit function $v(p, \bar{\xi})$ becomes strictly increasing on the entire interval $\left[p^{N}, p^{M}\right]$. In characterizing the optimal cartel price $p^{*}$ we must distinguish two cases depending on whether $p^{M}$ can be sustained under the constant legal upper bound $\bar{\xi}$. First, if $p^{M}$ can be sustained as a cartel price, then the monotonicity of $v(p, \bar{\xi})$ implies that the optimal cartel price is $p^{*}=p^{M}$, the minmax cartel profit is $v^{*}=v\left(p^{M}, \bar{\xi}\right)$, and the minimal cartel price is $\hat{p}=\pi^{-1}\left(\pi\left(p^{M}\right)-\beta \bar{\xi}\right)$. The optimal fine schedule imposes the maximal fine $\bar{\xi}$ on the most grave offence $p^{M}$, and all lower prices are fined below the legal upper bound. Second, if $p^{M}$ fails to be a cartel price, then monotonicity of $v(p, \bar{\xi})$ implies that $p^{*}<p^{M}$ is the maximal sustainable cartel price, which is the highest price $p \in\left[p^{N}, p^{M}\right]$ that solves $\pi(p)=(1-\delta) \pi^{o p t}(p)$.

With these observations in mind, we relate our results to the theory of marginal deterrence in Shavell (1992) and Wilde (1992) for individual offenders and two illegal acts under a constant legal upper bound and a common production of detection and conviction. ${ }^{7}$ These references derive that the optimal fine is non-decreasing in the level of harm in order to induce offenders to choose the least harmful act. For antitrust enforcement, illegal acts are represented by a continuum of cartel prices and both the cartel's illegal gains and society's

\footnotetext{
${ }^{7}$ The inspection and prosecution efforts of antitrust enforcement are such that a sector must be investigated in order to determine the actual cartel price set. The AA cannot target its activities on specific cartel prices beforehand. Therefore, in terms of Shavell (1992) and Wilde (1992), the production of antitrust enforcement classifies as common production of detection and prosecution.
} 
deadweight loss are increasing in the cartel price. Although the optimal fine schedule is nondecreasing in the cartel price, it is directly related to illegal gains rather than to society's harm. As a thought experiment in terms of two illegal acts under a constant fine schedule in our model, consider the case $p \in\left[\hat{p}, p^{*}\right)$ and, for a constant legal upper bound, $p^{*}$ that is either the monopoly price or the maximal sustainable cartel price. We have shown that the optimal fine for $p$ is strictly lower than the fine for $p^{*}$. For the remaining case $p \in\left(p^{N}, \hat{p}\right)$ and $p^{*}$, the optimal fine schedule cannot induce the cartel to choose the least harmful act because for such price even the zero fine is not low enough to provide the proper incentives. If that case arises in their model, Shavell (1992) and Wilde (1992) set the fine equal to the legal upper bound and this is in contrast to the principle of proportionality that would set the fine equal to zero. Recall that our results directly apply to individual illegal actions by ignoring the equilibrium condition in our model. To summarize, our results indicate how to generalize the results in Shavell (1992) and Wilde (1992) to the case of a non-constant legal upper bound and both individual and group violations with multiple concerted illegal actions in the context of antitrust enforcement.

\section{Concluding Remarks}

We provide a coherent framework to study the economic consequences of legal and economics principles in crime enforcement. Our analysis characterizes the optimal fine schedule that maximizes social welfare and we show that it coincides with the fine schedule that minmaxes the cartel's profit. This schedule remains below the legal ceiling, except at the cartel price where the minmax cartel profit is achieved under this legal ceiling, and there is a range of low cartel prices for which the fine is set to zero according to the legal lower bound. Hence, the main implication of our analysis is that the antitrust authority should not punish maximally overall, but punish in a smarter manner such that mild offenses are not fined at all. In general, our results call for a subtle reconsideration of the common wisdom in the economics of crime that setting the fine equal to the available legal upper bound always increases the 
effectiveness of deterrence.

By either adding or substituting other legal principles, one can easily assess the impact of such principles on the enforced cartel price. Therefore, our approach allows to quantify the economic costs of adapting society's legal principles through the differences in society's deadweight losses. For example, increasing maximum penalties by shifting the legal ceiling upwards decreases the cartel's minmax value, and consequently, reduces the cartel price. Although the antitrust authority should shrink the range of low cartel prices where it fines zero and raises the fine schedule elsewhere, the optimal fine schedule remains below the legal ceiling almost everywhere. As another example, imposing minimum fines, a popular call in recent politics, will enable the cartel to set a higher price. Therefore, positive minimum fines reduce social welfare and should never be imposed or, if they are currently implemented, they should be abolished. Our analysis provides a technique to adequately deal with such modifications of legal rules.

Furthermore, in the literature on antitrust enforcement, see Harrington (2010) and Buccirossi and Spagnolo (2007), it is often argued that corporate antitrust fines are insufficient to successfully deter cartel formation and that the legal upper bounds should be increased. We agree that increasing the legal upper bound is a right trend in general. But we also show that even in the presence of insufficient legal upper bounds the effectiveness of deterrence can still be improved by reducing fines for mild offences as our optimal fine schedule prescribes.

The derived optimal fine schedule can be related to the literature on marginal deterrence by Stigler (1971), Shavell (1992), and Wilde (1992). Our analysis shows how to generalize the results in Shavell (1992) and Wilde (1992) to the case of a non-constant legal upper bound and both individual and group violations with multiple concerted illegal acts in the context of antitrust enforcement.

Finally, our analysis can be easily extended to incorporate the optimal choice of inspection effort. In this case the optimal antitrust enforcement is characterized by a pair of instruments $\left(\beta^{*}, \xi^{*}\right)$ that minimizes dead-weight loss and the social cost of enforcement. We 
can characterize the optimal antitrust enforcement in two steps; first solve the optimal fine schedule for detection probability $\beta$, and then solve for the optimal level of the detection probability and the corresponding optimal fine schedule. Since the minimal optimal cartel price is continuous in $\beta$, there exists a socially optimal level of inspection efforts.

\section{Appendix: Optimal fine schedules when $\pi^{o p t}\left(p^{M}\right)>v^{*}$}

In Section 4, we mentioned that we may have technical issues related to the existence of the optimal fine schedule in case $\pi^{o p t}\left(p^{M}\right)>v^{*}$. This case corresponds to legal upper bounds that are relatively high so that $v^{*}$ is lower than $\pi^{o p t}\left(p^{M}\right)$. In this appendix we analyze this case in which the sustainability condition also plays a key role in the determination of the optimal fine schedule. We show that there are two intervals of cartel prices, one where the analysis of Section 4 still holds and one where a problem of existence of the optimal fine schedule arises.

By $\pi^{o p t}(\cdot)$ is increasing and $\pi^{o p t}\left(p^{M}\right)>v^{*}$, there exists a unique $\bar{p} \in\left[p^{*}, p^{M}\right)$ such that $\pi^{o p t}(\bar{p})=v^{*}$. For all $p \in\left[p^{N}, \bar{p}\right],(11)$ once more simplifies to $\xi(p) \geq \frac{1}{\beta}\left[\pi(p)-(1-\delta) v^{*}\right]$ as in Section 4 and, therefore, the same arguments imply that the fine schedule given by (12) is the optimal fine schedule on this interval of prices. For $p \in\left(\bar{p}, p^{M}\right]$, however, (10) and (11) become

$$
v(p, \xi)<\pi^{o p t}(p) \Leftrightarrow \xi(p)>\frac{1}{\beta}\left[\pi(p)-(1-\delta) \pi^{o p t}(p)\right]
$$

This implies that all prices $p \in\left(\bar{p}, p^{M}\right]$ are unsustainable as cartel prices. It is, however, impossible to weaken this strict inequality condition to a weak inequality. The reason for the strict inequality $v(p, \xi)<\pi^{o p t}(p)$ for $p \in\left(\bar{p}, p^{M}\right]$ is very different from the reason for the weak inequality $v(p, \xi) \leq v^{*}$ for $p \in[\hat{p}, \bar{p}]$. Recall that all $p \in[\hat{p}, \bar{p}]$ are sustainable and sustainability is not an issue because condition $v(p, \xi)=v^{*}$ ensures that the cartel would receive the minmax cartel profit even if the firms collude at price $p$. For any $p \in$ $\left(\bar{p}, p^{M}\right]$, however, equality instead of inequality in (14) would imply $v(p, \xi)=\pi^{\text {opt }}(p)>v^{*}$. 
Consequently, the sustainable cartel price $p$ would be more profitable than $v^{*}$ and the minimal cartel price $\hat{p}$ could not be an optimal cartel price. Hence, any cartel price $p \in\left(\bar{p}, p^{M}\right]$ must be unsustainable and this requires strict inequality.

Condition (14) poses two issues in characterizing the optimal fine for $p \in\left(\bar{p}, p^{M}\right]$ and resolving these issues distracts attention from the fact that the antitrust authority can secure the minimal cartel price $\hat{p}$. The first issue is that the right-hand side of (14) need not be non-decreasing. Within our domain of monotone fine schedules, the optimal fine schedule is therefore bounded from below on the interval $\left(\bar{p}, p^{M}\right]$ by the monotone function $\eta$ that is the least monotone function that satisfies

$$
\eta(p) \geq \pi(p)-(1-\delta) \pi^{o p t}(p) \quad \text { for } \bar{p}<p \leq p^{M} .
$$

The function $\eta$ exists, it is bounded from below by the constant function $\pi(\bar{p})-(1-\delta) v^{*}$ and bounded from above by the monotone function $\pi(p)-(1-\delta) v^{*} \leq \beta \bar{\xi}(p)$. Obviously, equality in (15) holds in case the right-hand side is non-decreasing. Otherwise, there will be a strict inequality for some or all $p \in\left(\bar{p}, p^{M}\right]$.

If case (15) would hold with a strict inequality for all $p \in\left(\bar{p}, p^{M}\right]$, which holds whenever the right-hand side is decreasing in $p$, our analysis is done and the function $\eta$ characterizes the optimal fine schedule $\hat{\xi}$ for $p \in\left(\bar{p}, p^{M}\right]$. The optimal fine schedule is then given by

$$
\hat{\xi}(p)= \begin{cases}0, & \text { for } p^{N} \leq p \leq \hat{p}, \\ \frac{1}{\beta}\left[\pi(p)-(1-\delta) v^{*}\right], & \text { for } \hat{p}<p \leq \bar{p}, \\ \frac{1}{\beta} \eta(p), & \text { for } \bar{p}<p \leq p^{M} .\end{cases}
$$

This fine schedule satisfies all legal principles and it implements the minimal cartel price $\hat{p}$ as the least optimal cartel price.

Unfortunately, the strict inequality in (15) may not hold for all $p \in\left(\bar{p}, p^{M}\right]$, which is the case in the classic Bertrand oligopoly for which $\pi^{o p t}(p)=n \pi(p)$, and this causes a second issue namely the least fine schedule $\eta$ fails as an optimal fine schedule on the interval $\left(\bar{p}, p^{M}\right]$. The consequence is that we cannot obey the principle of proportionality on $\left(\bar{p}, p^{M}\right]$. However, if we weaken this principle, the antitrust authority would be able to implement the minimal 
cartel price $\hat{p}$ as the least optimal cartel price within the domain of fine schedules that obey the other three legal principles. Note, however, that this issue is artificial. As is standard in many oligopoly models, we assume that money is perfectly divisible for technical convenience. In reality, there is a smallest money unit and one can break the equality $v(p, \xi)=\pi^{o p t}(p)$ by increasing $\xi$ by one smallest money unit. Here, the technical convenience of perfectly divisible money that served us well throughout the analysis turns against our main goal and we regard it as a technical matter of no practical importance.

Formally, consider the domain of monotone continuous fine schedules that satisfy both the lower and upper legal bounds. Within this domain, define the fine schedule $\hat{\eta}$ as a monotone continuous function on $\left(\bar{p}, p^{M}\right]$ such that $\lim _{p \rightarrow \bar{p}} \hat{\eta}(p)=\pi(\bar{p})-(1-\delta) v^{*}$ and $^{8}$

$$
\pi(p)-(1-\delta) \pi^{o p t}(p)<\hat{\eta}(p) \leq \pi(p)-(1-\delta) v^{*} \text { for } \bar{p}<p \leq p^{M}
$$

Then, $\hat{\eta}$ can replace $\eta$ in (16) and this modified fine schedule achieves the minimal cartel price $\hat{p}$ as the least optimal cartel price. Although $\hat{\eta}$ can approximate $\eta$ arbitrarily close, the strict inequality in (14) excludes that $\hat{\eta}$ coincides with $\eta$. So, we are able to satisfy three principles and by a hair the principle of proportionality on the interval $\left(\bar{p}, p^{M}\right]$.

Proposition 4 When $\pi^{\text {opt }}\left(p^{M}\right)>v^{*}>0$, the fine schedule given by

$$
\hat{\xi}(p)= \begin{cases}0, & \text { for } p^{N} \leq p \leq \hat{p}, \\ \frac{1}{\beta}\left[\pi(p)-(1-\delta) v^{*}\right], & \text { for } \hat{p}<p \leq \bar{p}, \\ \frac{1}{\beta} \hat{\eta}(p), & \text { for } \bar{p}<p \leq p^{M},\end{cases}
$$

implements $\hat{p}$ as the least optimal cartel price, it satisfies the legal principles of punishment fits the crime, the legal lower bound and the legal upper bound. Moreover, it satisfies the legal principle of proportionality on $\left[p^{N}, \bar{p}\right]$.

Proof. First, notice that $\hat{\xi}(\cdot)$ by (16) is continuous and monotonic. For $p \in\left(p^{N}, \bar{p}\right]$, the proof is identical to the proof of Proposition 3 , and every $p \in[\hat{p}, \bar{p}]$ can be sustained

\footnotetext{
${ }^{8}$ Many functions $\hat{\eta}$ exist, such as $\hat{\eta}(p)=\eta(p)+\beta \varepsilon(p-\bar{p})$ for small enough $\varepsilon>0$. Clearly, $\eta$ can be approximated arbitrarily close, but the principle of proportionality, i.e., $\varepsilon=0$, is ruled out.
} 
as a cartel price from which each firm earns the minmax cartel profit $v^{*}$. For $p \in\left(\bar{p}, p^{M}\right]$, $v(p, \hat{\xi})<\pi^{o p t}(p)$ implies that $p$ cannot be sustained as a cartel price. Therefore, the least optimal cartel price is equal to the minimal cartel price $\hat{p}$.

Although Proposition 4 does not pin down a unique optimal fine schedule, it provides a possible candidate for the optimal schedule in some special cases or if we weaken the legal principles. For example, if $\pi(p)-(1-\delta) \pi^{o p t}(p)$ is monotonically decreasing in $p$, then we can choose $\eta(p)$ to be the constant $\pi(\bar{p})-(1-\delta) \pi^{o p t}(\bar{p})=\pi(\bar{p})-(1-\delta) v^{*}$, and the corresponding $\hat{\xi}(\cdot)$ by (16) is the optimal fine schedule. Recall from Section 4 that our insights relate to the results in Block, Nold, and Sidak (1981) by letting the optimal (differentiable) fine schedule solve the differential equation $\beta \xi^{\prime}(p)=\pi^{\prime}(p)$ for $p \in\left[\hat{p}, p^{M}\right]$ under the additional condition $\xi\left(p^{*}\right)=\bar{\xi}\left(p^{*}\right)$. This can also be done here and would result in the function $\hat{\eta}$ given by $\hat{\eta}(p)=\pi(p)-(1-\delta) v^{*}$ on the interval $\left(\bar{p}, p^{M}\right]$. Our analysis shows that such fine schedule achieves the minimal cartel price $\hat{p}$, but that it involves excessive fining.

The fine schedule (16) coincides with the optimal fine schedule given in (12) for all $p \in\left(p^{N}, \bar{p}\right]$ and the intuition discussed in Section 4 remains valid. Recall that all these cartel prices are sustainable. For $p \in\left(\bar{p}, p^{M}\right]$, the fine function $\frac{1}{\beta}\left[\pi(p)-(1-\delta) v^{*}\right]$ is still feasible and by its construction yields a profit of $v^{*}$ to each individual firm. Because $v^{*}<$ $\pi^{o p t}(p)$ for all $p \in\left(\bar{p}, p^{M}\right]$, any price higher than $\bar{p}$ cannot be sustained if fine schedule $\frac{1}{\beta}\left[\pi(p)-(1-\delta) v^{*}\right]$ is imposed. However, it is possible to further lower the fine below $\frac{1}{\beta}\left[\pi(p)-(1-\delta) v^{*}\right]$ as long as these prices cannot be sustained as cartel prices. In other words, with any fine schedule such that

$$
\pi(p)-(1-\delta) \pi^{o p t}(p)<\beta \xi(p)<\pi(p)-(1-\delta) v^{*}
$$

each individual firm gets a profit that lies strictly between $v^{*}$ and $\pi^{o p t}(p)$. Because of the first inequality, the upper bound fails the principle of proportionality to deter cartel price $p$. Application of our insights to the boundary case $v^{*}=0$, which would violate condition (4), yields $\hat{p}=\bar{p}=p^{N}$ and $\frac{1}{\beta} \hat{\eta}(p)$ as the optimal fine schedule on $\left(p^{N}, p^{M}\right]$. For this boundary 
case, all issues discussed in this appendix hold.

To summarize, we regard the non-existence of the optimal fine schedule that satisfies all

four legal principles on $\left[p^{N}, p^{M}\right]$ as a technical matter of no practical importance. However, independent whether this issue arises, the facts remain that first.the antitrust authority can secure the minimal cartel price $\hat{p}$ by adopting one of the fine schedules given by (17) and second, that such fine schedules satisfy all four legal principles on the interval $\left[p^{N}, \bar{p}\right]$.

\section{References}

Becker, G.S. (1968) "Crime and punishment: an economic approach" Journal of Political Economy 76, 169-217.

Block, M., F. Nold, and J. Sidak (1981) "The deterrent effect of antitrust enforcement" Journal of Political Economy 89, 429-445.

Buccirossi, P. and G. Spagnolo (2007) "Optimal Fines in the Era of Whistleblowers - Should Price Fixers Still Go to Prison? in The Political Economy of Antitrust, by V. Goshal and J. Stennek (Eds.), Elsevier: Amsterdam.

Cooter, R. and T. Ulen (2007) Law and Economics, Addison Wesley Longman.

DOJ (2010) "US sentencing guidelines (chapter 8: Sentencing of organizations)" http://www.ussc.gov/2009guid/CHAP8.htm

EC (2006) "Guidelines on the method of setting fines imposed pursuant to article 23(2)(a) of regulation no 1/2003" Official Journal of the European Union (2006/C 210/02), Brussels.

Fish, M. (2008) "An eye for an eye: Proportionality as a moral principle of punishment" Oxford Journal of Legal Studies 28(1), 57-71.

Fudenberg, D. and J. Tirole (1991) Game Theory, MIT Press: Cambridge. 
Garoupa, N. (1997) "The theory of optimal law enforcement" Journal of Economic Surveys 11, 267-295.

Garoupa, N. (2001) "Optimal magnitude and probability of fines" European Economic Review 45, 1765-1771.

Harrington, J. (2004) "Cartel pricing dynamics in the presence of an antitrust authority" The Rand Journal of Economics 35, 651-673.

Harrington, J. (2005) "Optimal cartel pricing in the presence of an antitrust authority" International Economic Review 46, 145-170.

Harrington J. (2010) "Comment on Antitrust Sanctions " Competition Policy International 6, 41-51.

Houba, H., E. Motchenkova and Q. Wen (2012) "Competitive Prices as Optimal Cartel Prices" Economics Letters 114(1), 39-42.

Landes, M. (1983) "Optimal Sanctions for Antitrust Violations" The University of Chicago Law Review 50(2), 652-678.

Motta, M. and M. Polo (2003) "Leniency programs and cartel prosecution" International Journal of Industrial Organization 21, 347-379.

OECD (2002) "Fighting hard-core cartels: Harm, effective sanctions and leniency programs" OECD Report 2002, OECD, Paris, France, http://www.SourceOECD.org.

Polinsky, A. M. and Shavell, S. (1979) "The optimal trade-off between the probability and magnitude of fines " American Economic Review 69, 880-891.

Polinsky, A, M. and Shavell, S. (1984) "The optimal use of fines and imprisonment" Journal of Public Economics 24, 89-99.

Polinsky, A. M. and Shavell, S. (1991) "A note on optimal fines when wealth varies among individuals" American Economic Review 81, 618-621. 
Polinsky, A. M. and Shavell, S. (1992) "Enforcement costs and the optimal magnitude and probability of fines " Journal of Law and Economics 35, 133148.

Posner, R.A. (1976 \& 2001 second edition), Antitrust law: An Economic Perspective, University of Chicago Press, Chicago

Rey, P. (2003) "Towards a theory of competition policy" in Advances in Economics and Econometrics: Theory and Applications by M. Dewatripont, L. Hansen, and S. Turnovsky, Eds., Cambridge University Press.

Shavell, S. (1992) "A note on marginal deterrence" International Review of Law and Economics 12, 345-355.

Stigler, G. (1970) "The optimum enforcement of laws" Journal of Political Economy 78, 526-536.

Werden, G. and M. Simon (1987) "Why price fixers should go to prison" The Antitrust Bulletin 32, 91\%-93\%.

Wilde, L. (1992) "Criminal Choice, Nonmonetary Sanctions, and Marginal Deterrence: A Normative Analysis." International Review of Law and Economics 12, 333-44.

Wils, W. (2007) “The European commission's 2006 guidelines on antitrust fines: A legal and economic analysis" in World Competition 30(2). 